\title{
MAN IN THE SQUARE: UNA PARODIA DEL INDIVIDUO MODERNO*
}

Gül Yaşartürk ${ }^{(a)}$ y Rana İ̆neci Süzen $n^{(b)}$

MAN IN THE SQUARE: A PARODY OF MODERN MAN

MAN IN THE SQUARE: UMA PARÓDIA DO INDIVÍDUO MODERN

Fecha de recepción: 19 de noviembre del 2018

Fecha de aprobación: 5 de enero del 2019

Disponible en línea: 22 de febrero del 2019

\section{Sugerencia de citación:}

Yaşartürk, G. e İğneci Süzen, R. (2019). Man in the Square: una parodia del individuo moderno. Razón Crítica, 6, 155-168, doi: 10.21789/25007807.1450

Este ensayo fue traducido del inglés en su totalidad por Laura Fattori.

1 Este ensayo es una versión extendida de la presentación titulada Man in the Square; A Parody of Modern Individual, presentada el 9 de noviembre del 2018 en The Left Conference, Photography and Film Criticism. La conferencia tuvo lugar en la Facultad de Bellas Artes de la Universidad de Lisboa el 9 y 10 de noviembre del 2018.

(a) Gül Yaşartürk

Ph. D. de la Universidad de Dokuz Eylül

Profesora asociada del Departamento de Radio, Televisión y

Cine de la Facultad de Comunicación de Antalya Akdeniz University, Turquía https://orcid.org/0000-0002-3316-9828 gulyasarturk@yahoo.com

(b) Rana İğneci Süzen

Ph. D. de la Universidad de Dokuz Eylül

Profesora de los Departamento de Cine y Televisión de la Facultad de Bellas Artes de Antalya

Akdeniz University, Turquia

https://orcid.org/0000-0003-3681-7760

ranaigneci@hotmail.com 


\section{R E S U M E N}

The Square (2017) es una película de Ruben Ostlund en la que irónicamente critica el estado del individuo en la sociedad moderna en la que nació. Ruben Ostlund desarrolló el filme bajo la influencia de la filosofía de la Ilustración y, por este motivo, se enfoca en la razón. En nuestro estudio de esta película, pondremos en evidencia, con referencia a algunos conceptos de Jean Baudrillard, Arhur Danto y Donald Kuspits, que el arte contemporáneo — que se ha convertido en un producto y un objeto de consumo- ha perdido su significado. Asimismo, analizaremos la relación entre la Ilustración, el individuo y sus formas actuales, teniendo como referencia conceptos planteados por Max Horkheimer y Pankaj Mishra.

PALABRAS CLAVE: Ruben Ostlund, The Square, teoría del arte, la Ilustración. 


\begin{abstract}
A B S T R A C T
The Square (2017) is a film by Ruben Ostlund in which he ironically criticizes the state of the individual in modern society. Ruben Ostlund developed the film under the influence of the Enlightenment philosophy, therefore showing a special focus on reason. Using some concepts by Jean Baudrillard, Arthur Danto and Donald Kuspits In, our study of this film will highlight that contemporary art has lost its meaning, becoming a product and a consumption object. In addition, we will analyze the relationship between the Enlightenment, the individual and his current forms, taking as point of reference concepts explained by Max Horkheimer and Pankaj Mishra.
\end{abstract}

KEY WORDS: Ruben Ostlund, The Square, art theory, Enlightenment.

\title{
R E S U M O
}

Em The Square (2017), um filme de Ruben Ostlund, critica-se ironicamente o estado do indivíduo na sociedade moderna que nasceu. Ruben Ostlund desenvolveu o filme sob a influência da filosofia do Iluminismo, o que o levou a enfocar-se na razão. Utilizando como referência alguns conceitos de Jean Baudrillard, Arthur Danto e Donald Kuspits, neste estudo destacaremos que a arte contemporânea — que se tornou produto e objeto de consumo- perdeu seu significado. Além disso, a partir de conceitos apresentados por Max Horkheimer e Pankaj Mishra, analisaremos a relação entre o Iluminismo, o indivíduo e suas formas atuais.

PALAVRAS-CHAVE: ilustração, Ruben Ostlund, teoria da arte, The Square. 


\section{N T R O D U C C I Ó N}

La filmografía de Ruben Ostlund consiste en cuatro películas: Involuntary (2008), Play (2011), Force Majeure (2014) y The Square (2017). Las primeras dos no son películas que puedan describirse bajo la tradición del cine convencional. En estas, el documental y la ficción coexisten. Involuntary y Play presentan un estilo visual en el que la cámara es fija y lejana. Las reglas básicas de la imagen son ignoradas en cada cuadro: las cabezas de los personajes exceden los límites del encuadre, solamente vemos los pies de los personajes quienes continuamente entran y salen del cuadro, y a veces, incluso, contemplamos un encuadre vacío. No hay continuidad entre las transiciones en términos de una historia lineal. De hecho, Ostlund afirma que su objetivo principal es el de realizar documentales ${ }^{1}$. Sin embargo, es posible identificar similitudes temáticas o temas recurrentes a lo largo de su filmografía. Los temas enfatizados por el director hacen referencia al extranjero, al inmigrante - aquellos que en la sociedad se llaman 'otros'-, así como a la masculinidad y la familia.

Involuntary trata, en cinco narraciones independientes, los temas del conflicto entre la razón subjetiva y la racional, testigos silenciosos del crimen, prejuicios, hipocresía y homosocialidad ${ }^{2}$. En esta película vemos que el personaje de la profesora, quien es testigo de la violencia ejercida por un colega sobre un estudiante y que se siente culpable por no intervenir en la situación, reincide en los dos personajes masculinos que encontramos

1 En la entrevista de Xan Brooks a Ruben Östlund se dice: "all my films are about people trying to avoid losing face".

2 El término es propio del campo de la sociología y describe la inclinación por establecer relaciones sociales entre individuos del mismo sexo. Al no ser un término reconocido por la RAE, se ha decidido ponerlo en itálicas. (Nota de la traductora). https://www.theguardian.com/film/2018/ mar/11/ruben-ostlund-the-square-interview-force-majeure 
en la última parte de Play y, claramente, en Christian, el protagonista de The Square. Play está basada en los prejuicios y miedos de la sociedad sueca hacia los inmigrantes y extranjeros. Esta es una película que narra la historia de un grupo de chicos inmigrantes, quienes llevan a cabo, por medio de violencia psicológica, un juego mental, con el fin de dominar a los niños de clase más alta. En la escena principal del filme, los chicos inicialmente quieren ver el teléfono celular de uno de los niños más adinerados y luego sostienen que el teléfono fue robado. Desde el inicio, en la película queda claro que la razón de que los niños inmigrantes sean capaces de dominar a los acaudalados ciudadanos suecos es que la gente ve con aprensión a esos niños por el simple hecho de ser inmigrantes. Lo que es decisivo a este punto es la clase social y no, la etnicidad, ya que un personaje de la película, encarnado por un niño de origen asiático, hace parte del grupo dominante. Es interesante resaltar que las escenas de violencia en la película son construidas con encuadres lejanos, encuadres que alejan la acción. Como la cámara de Ostlund, cualquiera que presencie este tipo de violencia, elige verla de lejos, remotamente.

Como han tenido que entregar sus teléfonos y billeteras, los niños que abordan el tranvía sin tiquete son atrapados por el inspector, quien los multa. El oficial público, quien les da un discurso sobre lo incorrecto que es evadir las tarifas, a pesar de notar que todos son menores de 15 años, no se cuestiona sobre cómo llegaron ahí a mitad de la noche: él solamente aplica la ley.

En Force Majeure (2014) se narra la historia de Thomas, un padre que representa la razón subjetiva- que oscila entre sus propios intereses y los de su propia familia. Asimismo, la película revela que el hecho de hacer parte de una familia no es más que una simbología, un estatus sin sentido que lleva a encarnar algunos papeles específicos. Force Majeure es, también, una película sobre los estados de la masculinidad y homosocialidad que vemos en Involuntary.

Es The Square la película que hemos elegido analizar en este trabajo, ya que esta involucra los mismos temas que Ostlund había tratado en sus tres películas anteriores y se centra en el protagonista, interpretado por un actor principal, de acuerdo a las narrativas clásicas. En este ensayo, analizaremos The Square en dos partes. En la primera, las representaciones de arte contemporáneo en la película serán estudiadas en referencia a las reflexiones sobre el arte moderno de Jean Baudrillard (2010), Arhur Danto (2010) y Donald Kuspit, considerando que el arte contemporáneo es una reflexión de la soledad y de la inseguridad del mundo, y del 
hombre moderno. En la segunda, analizaremos las relaciones del protagonista, Christian, con los demás personajes siguiendo el marco teórico desarrollado por Pankaj Mishra (2017). Trataremos especialmente las reflexiones de Mishra, ilustradas en su artículo "Politics in the Age of Resentment: The Dark Legacy of the Enlightment”. También seguiremos las teorías de Max Horkheimer, con un énfasis en esas desarrolladas en "Eclipse of Reason", ya que es uno de los orígenes de las ideas de Mishra.

\section{El arte, el mundo y el hombre contemporáneos}

El arte es el medio a través del cual el ser consigue trascender su realidad existente o crear otras realidades propias. El arte le permite al ser humano completarse a sí mismo en una dimensión superior. Según Hegel, el arte es una manifestación del espíritu - es decir, naturaleza, verdad o razón (Bozkurt, 2014, p. 173)—. Para Heidegger, el arte es una de las formas por las cuales la verdad emerge (Bozkurt, 2014, p. 291). Sin embargo, el modernismo asumió la posición aristotélica del arte, la cual se basa en la mímesis, que puede definirse como la reflexión de las substancias. Para Baudrillard, este deseo de mímesis, de repetición, de producción y reproducción es el elemento más significativo y, a su vez, representa la base de la mentalidad y estilo de vida del mundo actual. Es por este motivo que la reproducción de la verdad se extendió de sobremanera en cada aspecto de la vida y, eventualmente, remplazó la verdad: ya no es posible mencionar una verdad original (Baudrillard, 2003, p. 15).

En su texto The Conspiracy of Art, Baudrillard afirma que el arte ha perdido sus poderes de ilusión y que la obra de arte se ha convertido simplemente en un objeto para ser exhibido y consumido visualmente (Baudrillard, 2010, p. 27). Lo que hoy es mostrado carece del significado simbólico, y este debe ser encontrado en la imagen misma, ya que la imagen reemplaza la verdad. Según Baudrillard, modernización nos ha arrebatado el poder de la imaginación. Hoy, las imágenes no son espejos que reflejan la realidad, sino que han sido convertidas en cosas que la reemplazan y la transforman en hiperrealidad (Baudrillard, 2010, p. 31). En consecuencia, el arte contemporáneo, la muerte del arte, representa un tipo de debacle de la modernidad y de la racionalidad.

Por su parte, Danto argumenta que la narrativa de la historia del arte,

que inició en el Occidente, pero que no se limitó a este, está estructurada en tres etapas: la era de la imitación, la de la ideología y la poshistórica, 
cuando todo era permisible. En el periodo de la mímesis, la crítica del arte estaba fundamentada en la verdad visual, mientras que, en el periodo ideológico, estaba basada en la dicotomía entre lo que es arte y lo que no puede serlo. La característica más importante del arte poshistórico fue, sin embargo, su divergencia de la filosofía, lo que significó el fin del arte y de la narrativa (Danto, 2010, p. 27).

Kuspit sostiene que el arte moderno ha perdido su relación con la creatividad, y que esta última es reemplazada por intereses sociales de lo cotidiano (Kuspit, 2010, p. 56). En el periodo que Kuspit denominó posartístico todo se vuelve un objeto comercializable. Kuspit ilustra su teoría dando el ejemplo de Piero Manzoni, quien firmó muchas latas que, se supone, contenían sus excrementos (Kuspit, 2010, p. 98). El autor sostiene que el objeto de arte ha sido convertido en mercancía y la producción del arte contemporáneo pertenece a un tipo de mercado, lo cual permite intercambiar las palabras arte y dinero. Kuspit asegura que el capitalismo ha destruido el arte al convertirlo en dinero (Kuspit, 2010, p. 161). Por el contrario, Baudrillard afirma que lo que acarrea el fin del arte, en lugar de su reificación, es el punto muerto del mundo moderno y racional (2010).

En este punto es posible ver los cambios socio-culturales existentes concentrándonos particularmente en el campo del arte y la peculiaridad de la situación nos expone un área infinita de ironía. Ostlund estructura The Square sobre esta misma ironía. La película presenta una crítica del arte contemporáneo que refleja a su vez una crítica al ser humano y la sociedad moderna. Además, esta muestra que el arte contemporáneo, en muchas maneras, coincide con los dilemas del modernismo.

En la escena inicial de The Square, Anne, la periodista americana, le pide a Christian que explique la frase "exposición y no exposición”, que se encuentra en página de Internet del Museo Real X. Christian le explica que trata sobre si un objeto, cuando es expuesto, puede ser considerado una obra de arte. Él usa el bolso de Anne como un ejemplo y le pregunta: "por ejemplo, si tomamos tu bolso y lo ponemos ahí, ¿eso haría de este una obra de arte?”. En esta escena Ostlund cuestiona el objeto del arte contemporáneo — cuyo primer ejemplo es considerado el urinal de Duchamp - y muestra cómo el objeto hoy se encuentra lejos de acarrear la radicalidad y el significado del trabajo de Duchamp. ¿Podría un bolso considerarse una obra de arte? Baudrillard asegura que incluso después de Duchamp se puede encontrar un significado en la propuesta de Andy Warhol de transformar un objeto ordinario en una obra de arte, y que 
las obras de arte moderno hoy no poseen el mismo significado y poder transformativo (Baudrillard, 2010, p. 43).

En la película, durante una entrevista en un evento formal de arte con invitados intelectuales y de élite, de repente un hombre con síndrome de Tourette insulta tanto al artista como al moderador. En esta escena del saboteo de un "evento formal de arte" hay un tono absurdo que le otorga a la película una inflexión crítica y una cierta burla del arte contemporáneo. En una escena similar, una obra de arte contemporáneo, compuesta por pequeños montones de arena y pedruscos, es barrida inadvertidamente por los aseadores del museo. ¿Qué podría ser más extraño que barrer una obra de arte? Una obra de arte que pueda barrerse probablemente no es algo que se les hubiera ocurrido a los artistas del renacimiento. En otra escena, una película comercial es preparada para la publicidad del proyecto Square - una de las obras más destacadas del museo-, lo que puede ser considerado tanto como un proyecto de arte moderno como una expresión simbólica de los límites del hombre moderno. El equipo de publicidad utiliza la palabra "producto" en referencia al proyecto: “¿Qué tanto interés periodístico es capaz de generar?, ¿implica algún conflicto?, ¿podríamos relacionarlo con tendencias o eventos actuales? De no ser así, estamos atascados a las vallas publicitarias y eso dificulta la generación de atención internacional”.

Todas estas declaraciones demuestran la estrecha relación entre la obra de arte, el dinero y el mercado. ¿Qué otra cosa podría cumplir el papel liberatorio que el arte le ofrece al ser humano en una época en que la obra de arte pierde su significado y contenido, si no el ser el medio por cual el hombre se transgrede a sí mismo? Cuando nada puede reemplazar tal función, la alienación del ser humano se profundiza, la falta de comunicación con el otro aumenta y el hombre se segrega aún más. El proyecto de arte Square es un símbolo de la soledad del individuo moderno, de la falta de empatía y del miedo hacia el otro. En la última parte de la película, Oleg ejecuta una performance en la gala preparada por el museo. En esta, interpreta a un mono en la jungla ${ }^{3}$. Una voz se escucha en el pasillo:

3 La interpretación del mono actuada por Oleg fue inspirada en Mad Dog, interpretada por Oleg Kulik. En esta interpretación, Kulik muerde severamente a la hija del curador, lo que lo lleva a tener problemas con la policía. Más información en https://www.slantmagazine.com/features/ article/interview-ruben-ostlund-on-the-square-and-the-social-contract 
Bienvenidos a la jungla. Pronto serán confrontados por un animal salvaje. Como todos ustedes saben, el instinto de caza se desencadena por la debilidad. Si demuestran miedo, el animal lo sentirá. Si intentan escapar, el animal los cazará. Pero si permanecen perfectamente quietos, sin mover un solo músculo, es posible que el animal no los note. Y ustedes podrán esconderse en la manada, seguros de que otra persona será la presa.

Estas palabras describen de manera muy acertada lo que el cuadrado significa para el individuo occidental. El cuadrado - protegidoamparado- que el individuo occidental ha dibujado para sí mismo, se transforma en un límite que lo protege de peligros, pero este, a su vez, destruye su comunicación con los demás, así como al principio mismo de "igualdad". Al individuo occidental dentro del cuadrado no le interesa lo que le sucede a los otros y llega incluso a no responder al llamado de ayuda, todo para proteger su propia área de bienestar. Mientras Oleg imita un mono primitivo, los invitados de la élite que asisten a la cena no se dan cuenta de que ellos mismos están adoptando las reglas de vida de una sociedad primitiva.

\section{Límites de los forasteros y nativos del cuadrado}

El eslogan del proyecto del cuadrado es "el cuadrado es el santuario, una zona de confianza y cuidado, todos compartimos derechos equitativos y responsabilidades dentro de sus límites". Sin embargo, a lo largo de la película, la imagen cuadrada es usada en una forma que rechaza este significado. En la película, Christian representa al individuo moderno viviendo en su zona segura, viviendo en su cuadrado. La película efectúa, a través de Christian, una crítica holística de la ideología de la Ilustración, la cual de cierto modo le dio forma a la civilización occidental actual. La crítica está basada en la manera en que el sujeto occidental se posiciona a sí mismo e incluye su relación con extranjeros e inmigrantes. Al inicio, a la salida de la estación del metro, Christian, quien se da cuenta que le han robado su teléfono y billetera, se hace a un lado de la vía y dice "necesito ayuda". Le pide a las personas que pasan que le presten un teléfono. Nadie se detiene. En ese momento somos testigos de la forma en que la clase alta occidental se convierte en el otro. La siguiente escena empieza con la interpretación —organizada por Christian- del 
mono de Oleg en el Museo Real X. Esta transición entabla una relación entre la situación de Christian, el primitivismo y la desesperación. El mismo tema se repite en la escena en que Christian pierde a sus hijas en el centro comercial. Cuando su llamado de ayuda no es atendido, termina pidiéndole ayuda a un mendigo a quien le había previamente mentido diciéndole que tenía efectivo para no darle dinero. En la última parte de la película, la interpretación de Oleg revela también cómo "la competencia y el emprendimiento individual, e intereses ilustrados propios" (Mishra, 2017, pp. 132-133) evolucionan hacia el egoísmo. Un ejemplo de este tipo de organización podríamos encontrarlo en las sociedades primitivas. Los diálogos y relaciones de Christian con las demás personas —incluyendo la periodista americana Anne, sus hijas, sus asistentes, el niño migrante, que es uno de los residentes del apartamento al que envía cartas de amenazas, y el hombre sin hogar con la que se encuentra todos los días- presentan el conflicto típico entre la razón subjetiva y la racional que Horkheimer analiza elaboradamente.

Según Horkheimer, la razón subjetiva o instrumental actúa de acuerdo a los principios de interés propio y de autoconservación, y calcula únicamente cómo lograr el objetivo sin cuestionar la racionalidad del objetivo deseado (Onur, 2016, pp. 80-81). La razón objetiva, no obstante, enfatiza los fines más que las herramientas e intenta reconciliar la vida humanista, incluyendo el interés propio y la autoconservación con el conocimiento de las verdades universales (Onur, 2016, p. 81). Horkheimer concluye que ambos puntos de la razón no representan dos modos distintos de la razón que son independientes entre sí. Sin embargo, lo que se requiere por parte de la filosofía es tratar de reconciliarlos en la práctica, si bien el mundo moderno sea dominado por la razón subjetiva. Las ideas del interés propio y de autopreservación han dominado las relaciones políticas y sociales. Por consiguiente, el énfasis debe hacerse en la razón objetiva, de la cual se espera que ponga estas relaciones en terreno sólido (Onur, 2016, p. 81). Del mismo modo, Mishra argumenta que si bien la razón humana de la era de la Ilustración es el único elemento para colocar el interés individual y social en el centro, la razón ha siempre ignorado muchos factores tales como el miedo de perder el honor, la dignidad o el estatus social que existe en la y determina el diario vivir. Este punto de vista excluye impulsos más complejos como el orgullo, el miedo a parecer vulnerable o el "construir una imagen" (Mishra, 2017, pp. 129-130). 
A este propósito, cabe recordar la escena, mencionada anteriormente, en la que Christian le envía cartas de amenazas a los 54 residentes del apartamento - al que su teléfono móvil también le envía señales para encontrar a los que han robado su billetera y teléfono-. Esta acción de Christian es sin duda un acto en el que desconoce la reputación y el honor de los residentes. Por esta razón el niño inmigrante confronta a Christian. El encarcelamiento de Christian en la razón subjetiva y en su soledad se percibe en una pequeña y oscura imagen cuadrada, en su apartamento, con las luces apagadas. En esta escena, después de una relación sexual, bajo la reticencia de Christian de darle a Anne el condón lleno de esperma, se expresa el temor de Christian a que ella tenga un hijo suyo (Gleiberman, 2017). Según Horkheimer, entre más intenso es el deseo del hombre de poseer, más profundo es el poder hegemónico que adquieren las posesiones sobre este (Horkheimer, 1998, pp. 146, 151). El individuo está condenado a ser únicamente un fenómeno biológico siempre que continúe siendo la encarnación de un ego, que es definido como la suma de las funciones que pretenden proteger su existencia. Para Christian, incluso su propio esperma se ha convertido una posesión sobre la que debe ejercer soberanía. A pesar de que Christian sabe que es un niño quien responde a la carta de amenaza, tiene miedo de él y su miedo se muestra en la escena en la que la cerradura de su puerta es forzada mientras él está solo en casa. El personaje se detiene ansioso en frente de una imagen con cuadrados concéntricos de varios tonos de marrón claro. Eventualmente, cuando la puerta se abre, Christian se siente aliviado de ver que son sus hijas, y cuando ellas salen de cuadro, la imagen de los cuadrados en la pared se vuelve borrosa y ocupa toda la imagen por un momento. El individuo dentro de las fronteras seguras delineadas por la Ilustración es extremadamente frágil, cobarde y solitario. Entre más tiene que perder, más cobarde es. En la última parte de la película, el espectáculo de danza de las chicas nórdicas, que son miembros de clase alta, se presenta con una imagen cuadrada impecable y estéril: la escena muestra a quién encierra el cuadrado "en realidad".

\section{Conclusiones}

La crítica del arte contemporáneo continúa siendo un concepto bastante popular en el mundo occidental y particularmente en las últimas décadas. Durante este periodo complejo, filósofos, pensadores e incluso artistas 
critican las obras de arte y al arte mismo, desde diferentes perspectivas. En el cine europeo, de la misma manera, muchos directores de cine producen películas criticando tanto la vida diaria del individuo occidental como los aspectos culturales tales como el arte, la alienación y la no comunicación. Ruben Ostlund es uno de esos cineastas que pone en el epicentro de su cine una crítica de los conceptos de arte, de individuo y del otro en las sociedades occidentales. Sin embargo, a diferencia de los demás, Ostlund en The Square presenta una perspectiva más holística ya que critica de manera paralela la vida social e individual y la producción artística. Considerando el arte como un medio de trascendencia de la realidad existente, un medio de creación de otras realidades o de finalización de sí mismo a un nivel superior, es posible ver que la producción artística contemporánea criticada en The Square es completamente mercantilizada y, por ende, sin sentido. Esta película es de gran importancia ya que demuestra que la producción de arte también está atrapada en una sociedad en la que las relaciones se han alienado y se han vuelto egoístas. La posición de Baudrillard, que considera la crítica del arte contemporáneo no solo como un problema del arte moderno o general, sino como el resultado de un sistema basado en el mundo moderno, en el capitalismo, en el dinero y el consumismo, es más que una mera crítica de arte como la perspectiva de la película. Respondiendo a una pregunta durante una sección de entrevistas sobre su libro The Conspiracy of Art, Baudrillard afirmaba que a él le interesaba la crítica del arte en cuanto esta posee algunas funciones que apoyan su examen de la cultura occidental. En cierto sentido, se puede asegurar que lo que Ruben Ostlund intenta conseguir en The Square es lo mismo que consigue Baudrillard. Ostlund describe cómo el individuo en el mundo occidental está atrapado en una cultura que emerge de los valores racionales de la Ilustración junto con la crítica del arte contemporáneo. El hecho de que el protagonista de la película sea curador del Museo Real X, que alguna vez fue palacio y la historia de la película esté basada en este museo como también las interpretaciones y exhibiciones que toman lugar en esta, respaldan la doble crítica de Ostlund. Es sorprendente que Ostlund ridiculice a su propia cultura, usando la comedia negra - típica del norte de Europa, uno de los lugares más destacados y que ampara los valores universales de la Ilustración-. A lo largo de la película, este acto de ridiculización es más que todo encarnado en el arte y las interpretaciones artísticas a las que siempre se ha atribuido gran importancia y que han sido consideradas portadoras de emociones y valores "elevados". En otras 
palabras, Ostlund no separa la irónica etapa del mundo del arte de la soledad, la falta de comunicación y el estar distanciado de la naturaleza humana de lo que el individuo moderno sufre. Él combina al arte y al individuo moderno en una crítica del sistema cultural y demuestra que tanto el arte como el hombre están atrapados dentro de las fronteras delineadas por la Ilustración.

El punto de vista de Ostlund sobre las relaciones del individuo occidental en The Square es una continuación de sus películas previas. Las contradicciones del individuo occidental, quien no interviene en las injusticias de las que ha sido testigo con el fin de permanecer en su área de seguridad, también aparecen en Christian. En sus acciones, vemos la dominación de la razón subjetiva analizada por Horkheimer. La motivación del interés propio y la autopreservación dirige las vidas de Christian y de todos los demás individuos a su alrededor. Por lo tanto, en la vida social presentada en The Square, todos pueden encarnar al 'otro' y todos pueden darle la espalda, en cualquier momento, a este con el propósito de preservar intereses propios y los espacios personales. El mismo individuo, de quien se esperaba que llevara a cabo una reconciliación entre la razón subjetiva y la razón objetiva de la era de la Ilustración, ha ocasionado que la razón subjetiva domine todos los aspectos de la sociedad. De esta manera, en la película, se hace hincapié en que el auge de la era de la Ilustración no está lejos ni difiere mucho de la sociedad primitiva, esa sociedad representada en la interpretación del personaje de Oleg al final de la película.

\section{Referencias}

Baudrillard, J. (2003). Simülakrlar ve Simülasyon [Simulacra and Simulation]. (Oğuz Adanır, trans.). Doğu Batı: Ankara.

Baudrillard, J. (2010). Sanat Komplosu [The Conspiracy of Art]. (Elçin Gen \& Iş1k Ergüden, trans.). İletişim:İstanbul

Bozkurt, N. (2014). Sanat Estetik Kuramları [Art and Aesthtics Theories]. Sentez: Ankara.

Danto, C. A. (2010). Sanatın Sonundan Sonra [After the end of Art]. (Zeynep Demirsü, trans.). İletişim:İstanbul

Gleiberman, O. (2017). Film Review: 'The Square'. Variety. Recuperado de https:// variety.com/2017/film/reviews/the-square-review-cannes-1202436834/

Horkheimer, M. (1998). Akıl Tutulması [Eclipse of Reason]. (Orhan Koçak, trans.). Metis: İstanbul. 
Kuspit, D. (2010). Sanatın Sonu [The End of Art]. (Yasemin Tezgiden, trans.). Metis: İstanbul

Mishra, P. (2017). Hınç Çăğnda Siyaset Aydınlanmanın Karanlık Mirası [Politics in the Age of Resentment: The Dark Legacy of the Enlightenment]. En Heinrich Geiselberger (ed.), Büyük Gerileme [The Great Regression]. (Merisa Şahin, Aslı Biçen, Ahmet Nüvit Bingöl, \& Orhan Kılıç, trads.). Metis:İstanbul.

Onur F. (2016). Horkheimer'da Akıl (Horkheimer's Understanding of

Reason). Kilikya Felsefe Dergisi (Cilicia Journal of Philosophy), 1. 74-89 